\title{
The Effects of Gender and Cost on Suspicion in Initial Courtship Communications
}

\author{
Mandy Walsh $^{1} \cdot$ Murray Millar $^{1} \cdot$ R. Shane Westfall ${ }^{1}$
}

Published online: 8 July 2016

(C) Springer International Publishing 2016

\begin{abstract}
The purpose of this study was to explore the influence of gender on suspicion towards claims made during courtship communications. It was hypothesized that participants would be more suspicious of claims made about reproductive relevant traits. To test the hypothesis, participants read a total of eight scenarios describing traits relevant to female reproduction (wealth, commitment, and child interest), traits relevant to male reproduction (physical beauty, youth, and sexual availability), and traits neutral to both genders (stargazing and game playing). After each scenario, participants indicated their suspiciousness about the veracity of the communication on five scales. As predicted, both men and women believed the neutral claim scenarios more than claims about reproductively significant traits. Women compared to men were more suspicious of claims related to wealth, commitment, and child interest, while men compared to women were more suspicious of claims related to physical beauty, youth, and sexual availability.
\end{abstract}

Keywords Courtship communication $\cdot$ Suspicion $\cdot$ Gender

Deception is common during human mate selection where both men and women engage in intersexual deceit in an effort to obtain high-quality mates (Dussault, Hojjat, and Boone 2013; Epstein 2007). A common intersexual deceptive strategy is to exaggerate or use false statements to convince prospective mates that they possess traits desired by the opposite

Murray Millar

Millarmurray@gmail.com

1 Department of Psychology, University of Nevada, Las Vegas, NV, USA sex (Bleske-Rechek and Buss 2006; Gonzaga, Keltner, Londahl, and Smith 2001; Toma and Hancock 2010).

Gender Differences in Mate Preferences Evolutionary psychologists drawing on Trivers' (1972) parental investment theory have specified a number of potential differences between the mate preferences of men and women. Trivers (1972) noted that biological differences between men and women (e.g., differences in reproductive capacity, energy and time to reproduce, and parental certainty) would result in sex-differentiated mating strategies and mate preferences. Specifically, women compared to men should be more interested in restricting reproduction, investing heavily in each child, and finding a mate that is willing do likewise. Consequently, when selecting long-term mates, it is beneficial for women to consider a man's willingness to commit to a long-term relationship and his ability and willingness to assist in raising offspring (Todd, Penke, Fasolo, and Lenton 2007). Alternatively, given the shorter reproductive life women, men will need to place more emphasis on cues related to the reproductive status such as youth. Further, the smaller initial investment in reproduction by men may allow them to place more emphasis on cues associated with immediate reproductive value such as beauty.

Numerous studies have found that women compared to men prefer mates who are rich in resources (e.g., Buss 1985; Buss et al. 1990; Fisman, Iyengar, Kamenica, and Simonson 2006; Goetz 2013; Gottschall, Martin, Quish, and Rea 2004; Iredale, Vugt, and Dunbar 2008; Hudson and Henze 1969; Asendorpf, Penke, and Back 2011; Buss, Shackelford, Kirkpatrick, and Larsen 2001), interested in commitment (e.g., Marlowe 2004; Hamida, Mineka, and Bailey 1998), and interested in child rearing (e.g., Hudson and Henze 1969; Hoyt and Hudson 1981; Buss et al. 2001). Alternatively, there are numerous studies have found that 
men compared to women place greater emphasis on a potential mate's availability for sexual relations (e.g., Regan et al. 2008), youthfulness (e.g., Marlowe 2004; Hudson and Henze 1969; Hamida et al. 1998), and physical beauty (e.g., Buss 1985, 1994; Buss et al. 2001).

Given the gender differences in mate preferences and the propensity to deceive prospective mates, it is not surprising that gender moderates the amount of deception about various traits. That is, men are more likely to make false claims about traits women desire and women are more likely to make false claims about traits men desire (Tooke and Camire 1991a, b; Keenan, Gallup, Goulet, and Kulkarni 1997). Deception about a prospective mate's traits can be extremely costly from an evolutionary perspective. As a result, it is very important for each gender to assess the veracity of these claims, particularly about reproductively relevant traits.

However, the veracity of claims made at the beginning of courtship are often difficult to verify. Haselton and Buss (2000) suggest that in this type of situation, persons exhibit innate biases that limit the cost of being deceived. The mechanism employed to limit cost involves defaulting to the judgment that is least costly if incorrect. In the case of claims about putative traits, the deciding factor would be the relative costs of believing the claim versus the costs of not believing the claim. Consequently, during the initial stages of courtship, it may be reasonable for each gender to default to suspicion about claims regarding desired traits. For example, a woman who believes a false claim about wealth could be placed in the high-cost situation of rearing a child in poverty. Whereas, rejecting a true claim of wealth may only defer mating until the claim can be verified. Indeed, there is already a considerable body of evidence demonstrating women are skeptical of men's claims of commitment (La France, Henningsen, Oates, and Shaw 2009).

The current study attempts to extend this research by looking for gender differences in suspicion of claims that would be of high cost to each sex if proven false. It was hypothesized that participants will be more suspicious of claims made about reproductive relevant traits. Specifically, women will be more suspicious of claims made by prospective mates about wealth, commitment, and child interest, while men will be more suspicious of claims made by prospective mates about physical beauty, youth, and sexual availability.

Beyond examining our central hypothesis, we wanted to explore the possible moderating role of mate value. Research has indicated that persons high in mate value are more selective when choosing mates (e.g., Buss 2008). It is conceivable that increases in selectivity are accompanied by increases in suspicious of courtship claims, i.e., in order to be selective, a person would need to question the veracity claims made by a prospective mate. If this correct, we would expect our hypothesized effects to be stronger with high mate-value participants.

\section{Methods}

\section{Participants}

Participants were 165 women and 68 men recruited from a large urban university in the southwestern USA. The study employed an electronic signup procedure operated by the psychology department to recruit participants. The study did not offer monetary compensation to the participants but did give the participants the opportunity to earn class credit. The average age of the participants was $20(\mathrm{SD}=3.35)$, and the range of ages was 18 to 39 years of age. Forty-three percent of the participants were of European descent, $14 \%$ were of Hispanic descent, $10 \%$ were of Filipino descent, $7 \%$ were of African descent, and $26 \%$ were from other groups. Participation in the study was limited to persons indicating that they were heterosexuals and over 18 years of age. All research was approved by the appropriate university committee on research ethics.

\section{Procedures}

The study was conducted using an online survey program. Once registered, participants were given a direct link to the study. After opening the link participants were shown a general instruction page that included a brief summary of the study. All participants then filled out a demographic questionnaire that asked them to indicate their age, ethnic background, and gender. In addition, the participants were asked to indicate whether they were in an intimate romantic relationship. Next, eight written scenarios were randomly presented to each participant that described an email conversation between a man and woman who have never met. For female participants, a man was sending an email to a woman, and for male participants, this was reversed with a woman sending an email to a man. In each of the scenarios, the recipient of the email was described as a person looking for a long-term intimate relationship who was receiving an email from a potential suitor. In the email, the sender described himself or herself.

Scenario Relevance/Cost In three of the scenarios, the sender focused on characteristics that should be particularly costly to women (wealth, commitment, and child interest). In the wealth scenario, the sender described his/her luxurious life style and possessions (e.g., amazing house); in the commitment scenario, the sender expressed a desire for a long-term commitment (e.g., a desire settle down); and in the child interest scenario, the sender described his/her ability and desire to interact with children. In another three scenarios, the sender focused on characteristics that should be particularly costly to men (physical beauty, youth, and sexual availability). In the physical beauty scenario, the sender described him/herself as very attractive (e.g., toned body); in the sexual interest scenario, the sender expressed an interest in sex (e.g., open to his/her 
sexuality); and in the youth scenario, the sender described $\mathrm{him} /$ herself as youthful. In the remaining two scenarios, the sender focused on characteristics that should not be particularly relevant to either men or women (interest in stargazing and interest in playing board games).

After reading each scenario, participants were asked to rate the truthfulness of the sender of the email on three scales with endpoints of 1 (deceitful) and 5 (truthful), 1 (not believe) and 5 (believe), and 1 (not skeptical) and 5 (skeptical). In addition, participants were asked to indicate how positive they were towards the email sender on a scale with endpoints of 1 (negative) and 5 (positive) and whether the receiver of the email should reply to the sender on a scale with endpoints of 1 (not likely) and 5 (likely).

To explore whether the mate value of the participant moderated our hypothesized effects, following the scenarios, participants completed the multi-dimensional measure of mate value inventory (MVI) developed by Kirsner, Figueredo, and Jacobs (2003). The MVI requires the participant to indicate the extent to which 17 attributes apply to him/herself on five-point scales with endpoints of 1 (extremely low on this trait) and 5 (extremely high on this trait). Each of the attributes presented in the scale relate to a characteristic that would be of interest to a romantic partner (e.g., intelligent, healthy, attractive face, and faithfulness). The scale has been used extensively to measure mate value (Jones, Figueredo, Dickey, and Jacobs 2007) and has demonstrated acceptable inter-item reliability in the past research $(\alpha=.78$, Jones et al. 2007 and $\alpha=.83$, Fisher, Cox, Bennett, and Garvik 2008).

\section{Results}

The primary hypothesis stated that the believability of the statements in the scenarios would be influenced by the gender of the participant and the evolutionary cost of deception. To test this hypothesis, the participants' responses to the believability, truthfulness, and skepticism items at the end of each scenario were summed for each participant to create a believability index for each of the eight scenarios. The skepticism item was reverse coded. These indexes were internally consistent (wealth $\alpha=.82$, child friendliness $\alpha=.81$, commitment $\alpha=.78$, attractiveness $\alpha=.80$, youth $\alpha=.83$, sex $\alpha=.66$, monopoly $\alpha=.70$, stargazing $\alpha=.77$ ). The three indexes hypothesized to be most relevant to women (wealth, commitment, and child interest) were averaged for each participant to create an overall women relevant believability score. Then, the three indexes most relevant to men (physical beauty, youth, and sexual availability) were averaged to produce a male relevant believability score. Finally, the two control indexes (game playing and stargazing) were averaged to produce a control believability score. Consequently, three scores were created for each participant that reflected how much they believed the female relevant scenarios, how much they believed the male relevant scenarios, and how much they believed the control scenarios.

These three scores were analyzed in a 2 (male vs. female Participant) $\times 3$ (female costly, male costly, control scenarios) analysis of variance (ANOVA) with repeated measures assumed on the last factor ${ }^{1}$. This analysis produced a main effect for the cost of the scenario, $F(2,462)=55.81, p<.001$, $\eta_{p}{ }^{2}=.20$. Bonferroni's post hoc comparisons revealed that the control scenarios $(M=11.20, \mathrm{SD}=1.97)$ were believed significantly more than either the female costly scenarios $(M=9.60, \mathrm{SD}=2.17, p=.003)$ or male costly scenarios $(M=9.85, \mathrm{SD}=2.11, p=.005)$. There was no significant difference in believability between the male costly and female costly scenarios, $p=.40$. Furthermore, as predicted, this main effect was qualified by a significant interaction between gender of the participant and scenario type, $F(2,462)=16.81$, $p<.001, \eta_{p}{ }^{2}=.07$. Females were significantly less likely to believe a female costly scenario than males, $F(1$, $164)=20.21, p<.001, \eta_{p}{ }^{2}=.11$. Conversely, males were significantly less likely to believe a male costly scenario than females, $F(1,67)=11.10, p<.001, \eta_{p}{ }^{2}=.14$. There were no significant differences between males and females on the control scenarios, $p>.05$ (see Figure 1).

A further set of analyses was conducted to examine whether a particular scenario was responsible for the effects. For example, is it possible that participants were reacting differently to only one of the female or male costly scenarios. To explore this possibility, the believability scores for each of the six scenarios were analyzed in a separate one factor (gender of participant) ANOVA. For the three female costly scenarios, all means were in the predicted direction. With wealth scenarios, women were less believing $(M=7.04, \mathrm{SD}=2.87)$ than men $(M=8.21, \mathrm{SD}=3.06), F(1,231)=7.70, p=.006, \eta_{p}{ }^{2}=.03$; with commitment scenarios, women were less believing $(M=10.05, \mathrm{SD}=2.96)$ than men $(M=11.68, \mathrm{SD}=2.64)$, $F(1,231)=15.33, p<.001, \eta_{p}{ }^{2}=.06$; and with child interest scenarios, women were less believing $(M=10.51, \mathrm{SD}=2.96)$ than men $(M=11.79, \mathrm{SD}=2.39), F(1,231)=9.974, p=.002$, $\eta_{p}{ }^{2}=.04$. Conversely, with physical beauty scenarios, men were less believing $(M=7.17, \mathrm{SD}=2.81)$ than women $(M=7.98, \mathrm{SD}=2.73), F(1,231)=4.11, p=.05, \eta_{p}{ }^{2}=.02 ;$ with youth scenarios, men were less believing $(M=10.35$, $\mathrm{SD}=3.18)$ than women $(M=11.87, \mathrm{SD}=2.68), F(1$, $231)=13.83, p<.001, \eta_{p}^{2}=.06$; and with sexual availability scenarios, there was a nonsignificant tendency for men to be less believing $(M=10.27, \mathrm{SD}=3.24)$ than women $(M=10.92$, $\mathrm{SD}=2.48), F(1,231)=2.63, p=.10, \eta_{p}^{2}=.011$.

\footnotetext{
${ }^{1}$ When mate value was added to the original set of analyses, it failed to produce any significant effects and subsequently was excluded from further consideration.
} 


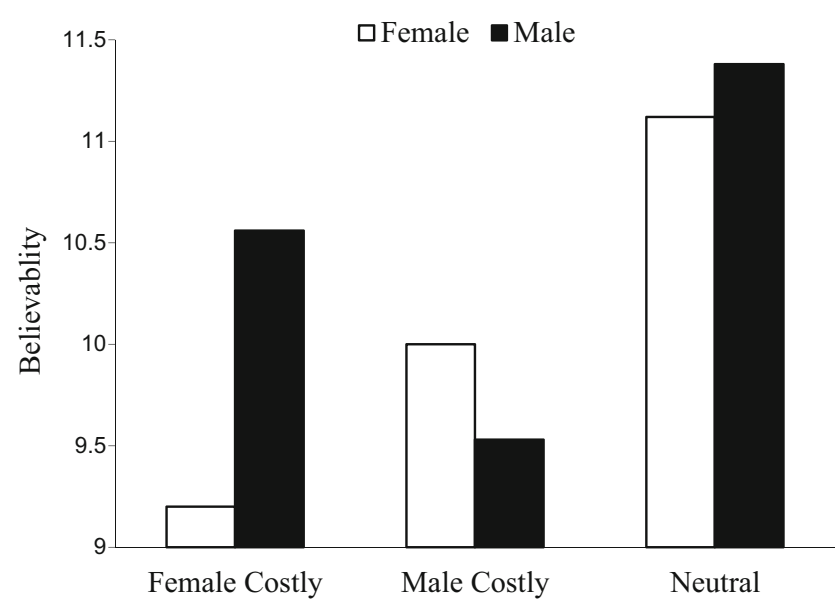

Fig. 1 Mean believability of scenarios as a function of gender and relevance of the cost of deception. Higher numbers indicate the participants believed the statements more

Control Variables Because factors such as age and dating experience have been linked to increased deception detection abilities (Barnacz, Amati, Fenton, Johnson, and Keenan 2009), several control analyses were performed. It is possible that this increased ability to detect deception is produced by an increase in suspicion about claims made by potential partners. The impact of relation status was examined by adding it to the main analysis to create a 2 (relationship status) $\times 2$ (male vs. female participant) $\times 3$ (female costly, male costly, control scenarios) ANOVA with repeated measures assumed on the last factor. Relationship status was not involved in any significant effects, $p(\mathrm{~s})>.20$. The impact of the age of the participant on believability was examined by separate correlations between age and the believability scores for the three types of scenarios. Not surprisingly, given age limited variability, the age of the participants was not related to the believability of male costly $(r=.08, p>.05)$, female costly $(r=-.05, p>.05)$, or neutral scenarios $(r=.01, p>.05)$.

\section{Discussion}

The purpose of this study was to investigate whether there would be gender differences in suspicion across topics where deception would be higher in cost to either men or women. The findings from the study provide support for the predictions. First, as expected, both men and women participants believed the neutral claim scenarios more than claims about reproductively significant traits. Second, as expected, we found that gender moderated this relationship. Women compared to men were more suspicious of claims related to wealth, commitment, and child interest, while men compared to women were more suspicious of claims related to physical beauty, youth, and sexual availability. Despite obtaining a pattern of results that supported our hypothesis, it is important to point out that the analyses produced relatively small effect sizes.

These findings are consistent with the literature that has demonstrated gender differences in preferences for reproductively relevant traits (Buss et al. 2001; Gottschall et al. 2004; Regan et al. 2008). The reproductively relevant traits (e.g., wealth, commitment) suggested by this literature were the same traits that aroused suspicion. Not only do persons indicate these traits are more desirable but they also evaluate claims about these features differently from other features. Further, the results directly replicate the commitment skepticism effect found in the extant literature (Haselton and Buss 2000). That is, in the current study, women participants were less likely to believe men's claims about the desirability of being in a committed relationship.

However, the finding that men tended to be more suspicious of women's claims about sexual availability might appear to contradict Hazelton and Buss' (2010) sexual overperception findings. Sexual over-perception is the tendency for men to perceive more sexual interest in women than is actually present. If men tend to over perceive sexual interest, then why would men in the current study be skeptical of women's claims of sexual availability? It would seem that believing claims of sexual availability would dovetail nicely with over-estimation of sexual interest. There are a couple of important differences between the present research and research on sexual over-perception. First, the sexual overperception research requires men to estimate sexual interest as opposed to evaluating the veracity of claims about sexual availability. The evaluation of veracity seems likely to invoke different cognitive processes than the assessment of sexual interest. The aim of the veracity judgment is to assess the truthfulness of the prospective mate. While men over perceive sexual interest, they may still be suspicious of direct claims made by women, especially when these claims are relevant to their reproductive success. Second, the sexual over-perception research focused on sexual availability to the perceiver as opposed to sexual availability in general. There may be less impetus for men to distort the overall availability of a woman as opposed to distorting her specific availability to him.

Although the results are consistent to the hypotheses, the current study has a couple of limitations. First, while this study suggests that men and women's veracity judgments might be "programmed" to respond to claims about certain traits, the results do not clearly demonstrate that this programming was due to evolutionary design. Drawing on error management theory, we framed our research as an innate tendency to exhibit systematic biases that limit the cost of being deceived (Haselton and Buss 2000). However, our methods do not allow us to disentangle biological programming from a straightforward learning explanation. It might be that men and women learn through repeated interactions that the opposite sex is likely to dissemble about certain traits, i.e., instead of innate 
bias, it may be more of a learning effect. If this is the case, we might expect suspicion about trait claims to increase with age and the number of relationship experiences. Although we did not find age or relationship effects in the current study, this may be due to the restricted age range of sample.

Second, the study relied on self-reports and scenarios, i.e., participants were asked to indicate whether they would believe statements made by the persons presented in the scenarios. While there is evidence that participants can give selfreports that will predict their behavior (Shrauger, Ram, Greninger, and Mariano 1996), this type of procedure may allow participants to place less emphasis on variables that might impact their judgements under more real-world conditions. Future research might address this concern by examining suspicion that occurs in actual relationships. Specifically, existing couples could be asked to recall their suspicions about claims made by their partners at the beginning of their relationship.

\section{Conclusion}

In the present study, veracity judgments about reproductively relevant traits seem to conform to the pattern suggested by evolutionary approaches. Both sexes become more suspicious of claims about traits most relevant to their sex's reproduction.

Overall, the research highlights the importance of exploring how persons make veracity judgments about claims regarding reproductively relevant traits.

Compliance with Ethical Standards All research was approved by the appropriate university committee on research ethics.

\section{References}

Asendorpf, J. B., Penke, L., \& Back, M. D. (2011). From dating to mating and relating: predictors of initial and long-term outcomes of speeddating in a community sample. European Journal of Personality, 25, 16-30. doi:10.1177/0956797611414725.

Barnacz, A., Amati, F., Fenton, C., Johnson, A., \& Keenan, J. P. (2009). Deception and dating: knowledge of tactics may improve detection accuracy. Journal of Social, Evolutionary, and Cultural Psychology, $3(1), 1-8$.

Bleske-Rechek, K., \& Buss, D. M. (2006). Sexual strategies pursued and mate attraction tactics deployed. Personality and Individual Differences, 40, 1299-1311. doi:10.1016/j.paid.2005.11.014.

Buss, D. M. (1985). Human mate selection. American Scientist, 73, 4751.

Buss, D. M. (1994). The strategies of human mating. American Scientist, 82(3), 238-249.

Buss, D. M. (2008). Attractive women want it all: good genes, economic investment, parenting proclivities, and emotional commitment. Evolutionary Psychology, 6, 134-146.

Buss, D. M., Abbott, M., Angleitner, A., Biaggio, A., Blanco-Villasenor, A., Bruchon-Schweitzer, M., et al. (1990). International preferences in selecting mates: a study of 37 societies. Journal of Cross-Cultural Psychology, 21, 5-47. doi:10.1177/0022022190211001.

Buss, D. M., Shackelford, T. K., Kirkpatrick, L. A., \& Larsen, R. J. (2001). A half century of American mate preferences: the cultural evolution of values. Journal of Marriage and the Family, 63, 491503. doi:10.1111/j.1741-3737.2001.00491.x.

Dussault, M., Hojjat, M., \& Boone, R. T. (2013). Machiavellianism and dating: deception and intimacy. Social Behavior and Personality: An International Journal, 41, 283-295.

Epstein, R. (2007). The truth about online dating: the hype is huge, and the findings are somewhat disturbing - but the future of online dating looks good. Scientific American Mind: 28-35.

Fisher, M., Cox, A., Bennett, S., \& Garvik, D. (2008). Components of self-perceived mate value. The Journal of Social, Evolutionary, and Cultural Psychology, 2, 156-168.

Fisman, R., Iyengar, S. S., Kamenica, E., \& Simonson, I. (2006). Gender differences in mate selection: evidence from a speed dating experiment. The Quarterly Journal of Economics, 121(2), 673-697.

Goetz, C. (2013). What do women's advertised mate preferences reveal? An analysis of video dating profiles. Evolutionary Psychology, 11, 383-391.

Gonzaga, G. C., Keltner, D., Londahl, E. A., \& Smith, M. D. (2001). Love and the commitment problem in romantic relations and friendship. Journal of Personality and Social Psychology, 81, 247-262. doi:10.1037/0022-3514.81.2.247.

Gottschall, J., Martin, J., Quish, H., \& Rea, J. (2004). Sex differences in mate choice criteria are reflected in folktales from around the world and in historical European literature. Evolution and Human Behaviour, 25, 102-112. doi:10.1016/S1090-5138(04)00007-8.

Hamida, S. B., Mineka, S., \& Bailey, J. M. (1998). Sex differences in perceived controllability of mate value: an evolutionary perspective. Journal of Personality and Social Psychology, 75, 953-966. doi:10.1037/0022-3514.75.4.953.

Haselton, M. G., \& Buss, D. M. (2000). Error management theory: a new perspective on biases in cross-sex mind reading. Journal of Personality and Social Psychology, 78, 81-91. doi:10.1037/00223514.78.1.81.

Hoyt, L. L., \& Hudson, J. W. (1981). Personal characteristics important in mate preferences among college students. Social Behavior and Personality, 9, 93-96.

Hudson, J. W., \& Henze, L. F. (1969). Campus values in mate selection: a replication. Social Forces, 31, 772-775. doi:10.2307/349321.

Iredale, W., Vugt, M., \& Dunbar, R. (2008). Showing off in humans: male generosity as a mating signal. Evolutionary Psychology, 6, 386-392.

Jones, D., Figueredo, A., Dickey, E., \& Jacobs, J. (2007). Relations among individual differences in reproductive strategies, sexual attractiveness, affective and punitive intentions, and imagined sexual emotional infidelity. Evolutionary Psychology, 5, 387-410.

Keenan, J. P., Gallup, G., Goulet, N., \& Kulkarni, M. (1997). Attributions of deception in human mating strategies. Journal of Social Behavior and Personality, 12, 45-52.

Kirsner, B., Figueredo, A., \& Jacobs, W. (2003). Self, friends, and lovers: structural relations among Beck Depression Inventory scores and perceived mate values. Journal of Affective Disorders, 75, 131148. doi:10.1016/S0165-0327(02)00048-4.

La France, B. H., Henningsen, D. D., Oates, A., \& Shaw, C. M. (2009). Social-sexual interactions? Meta-analyses of sex differences in perceptions of flirtatiousness, seductiveness, and promiscuousness. Communication Monographs, 76(3), 263-385. doi:10.1080 /03637750903074701.

Marlowe, F. W. (2004). Mate preferences among Hadza hunter-gatherers. Human Nature, 15, 365-376. doi:10.1007/s12110-004-1014-8.

Regan, P. C., Levin, L., Sprecher, S., Christopher, F. S., \& Gate, R. (2008). Partner preferences: what characteristics do men and women desire in their short-term and long-term romantic partners? Journal 
of Psychology and Human Sexuality, 12, 1-21. doi:10.1300/J056 v12n03 01.

Shrauger, J. S., Ram, D., Greninger, S. A., \& Mariano, E. (1996). Accuracy of self-predictions versus judgements by knowledgeable others. Personality and Social Psychology Bulletin, 22, 1229-1241.

Todd, P. M., Penke, L., Fasolo, B., \& Lenton, A. P. (2007). Different cognitive processes underlie human mate choices and mate preferences. Proceedings of the National Academy of Sciences of the United States of America, 104(38), 15011-15016.

Tooke, W., \& Camire, L. (1991a). Patterns of deception in intersexual and intrasexual mating strategies. Ethology and Sociobiology, 12, 345364. doi:10.1016/0162-3095(91)90030-T.
Toma, C. L., \& Hancock, J. T. (2010). Looks and lies: the role of physical attractiveness in online dating self-presentation and deception. Communication Research, 37(3), 335-351. doi:10.1177 /0093650209356437.

Tooke, W., \& Camire, L. (1991b). Patterns of deception in intersexual and intrasexual mating strategies. Ethology and Sociobiology, 12(5), 345-364.

Trivers, R. L. (1972). Parental investment and sexual selection. In B. Campbell (Ed.), Sexual selection and the descent of man, 18711971 (pp. 136-179). Chicago, IL: Aldine. 